phải truyền máu cũng như giảm số lượng máu cần truyên. Tác giả đánh giá đây là một phương tiện có khả năng tạo ra xâm lấn tối thiểu, có thể giúp ích cho các phẫu thuật khó như phẩu thuật ở tuyến yên. Trong nghiển cứu này chúng tồi cũng gặp ít bệnh nhân có tai biến xơ dính, đóng vảy trong hốc mũi và tỷ lệ gặp giữa nhóm nghiên cứu và nhóm chứng không có khác biệt. Vì vậy, khi sử dụng hê thống Aquamantys là an toàn và không ảnh hưởng tới tỷ lệ tai biến của phẫu thuật nội soi mũi xoang.

\section{KẾT LUÂNN}

Hệ thống Aquamantys giúp giảm thời gian phẫu thuật, giảm lượng máu mất trong phẫu thuật thông qua thời gian phẫu thuật của nhóm nghiên cứu là $78,9 \pm 22,4$ phút ngẳn hơn có ý nghĩa thống kê so với nhóm chứng là $94,0 \pm$ 21,5 phút với $p<0,05$. Và lượng máu mất ở nhóm nghiên cứu là $86,7 \pm 42,3 \mathrm{ml}$ thấp hơn có ý nghĩa thống kê so với nhóm chứng là $116,0 \pm$ $41,8 \mathrm{ml}$ với $\mathrm{p}<0,05$. Triệu chứng cơ năng theo thang VAS cho thấy sau phẫu thuật 5 ngày ở nhóm nghiên cứu có xu hướng nhẹ hơn so với nhóm chứng $(p>0,05)$ và sau mố 2 tuần và 2 tháng ở nhóm nghiên cứu tương đương với nhóm chứng $(p>0,05)$. Triệu chứng thực thể sau phẫu thuật 2 tháng giữa 2 nhóm không thấy khác biệt với $p>0,05$. Bênh nhân có dính hay xơ seo trong hốc mũi thấp, không khác nhau giữa nhóm nghiên cứu và nhóm chứng. Vì vậy, khi sử dụng hệ thống Aquamantys là an toàn và không ảnh hưởng tới tỷ lệ tai biến của phẫu thuật nội soi mũi xoang.

\section{TÀI LIÊU THAM KHẢO}

1. Fokkens WJ, Lund VJ, Hopkins $C$, et al (2020). European Position Paper on Rhinosinusitis and Nasal Polyps. Rhinology: 58 (Suppl S29):1-464.

2. Bram R, Fiore S, McHugh D, Samara GJ, Davis RP (2017). Hemostasis in endoscopic endonasal skull base surgery using the Aquamantys bipolar sealer: Technical note. J Clin Neurosci. 41:81-85.

3. Phạm Trung Kiên (2019). Nghiên cứu đặc điểm lâm sàng, cắt lớp vi tính, mô bệnh hoc các tổn thương xoang một bên. Luận văn chuyên khoa cấp II, Trường đại học Y Hà Nội.

4. Lế Đức Đông (2019). Nghiên cứu đặc điểm lâm sàng, cận lâm sàng và đánh giá kết quả điều trị phẫu thuật của viêm mũi xoang do nấm. Luận văn chuyên khoa cấp II, Trường đại học Y Hà Nội. tr78.

5. Yong Lee, Jae. (2008). Unilateral paranasal sinus diseases: analysis of the clinical characteristics, diagnosis, pathology, and computed tomography findings. Acta Oto-Laryngologica, 128(6), 621-626.

6. Marulanda G. A., Ulrich S. D., Seyler T. M. et al. (2008), Reductions in blood loss with a bipolar sealer in total hip arthroplasty, Expert review of medical devices, 5(2), 125-131.

7.Clement R. C., Kamath A. F., Derman P. B. et al. (2012), Bipolar sealing in revision total hip arthroplasty for infection: efficacy and cost analysis, The Journal of arthroplasty, 27(7), 1376-1381.

8. Ackerman S. J., Tapia C. I., Baik R. et al. (2014), Use of a bipolar sealer in total hip arthroplasty: medical resource use and costs using a hospital administrative database, Orthopedics, 37(5), e472-e481.

\title{
KẾT QUẢ ĐIỀU TRI CHẤN THƯƠNG NGỰC KÈM THEO CHẤN THƯƠ'NG SO NÃO Có DẪN LƯU MÀNG PHỔI ĐƠ'N THUẦN TẠI BỆNH VIỆN HỮU NGHI VIỆT ĐỨC
}

\section{TÓM TẮT}

Đắt vấn đề: Chấn thương ngực kèm theo chấn thương sọ não có dẫn lưu màng phổi đơn thuân là một bệnh cảnh lâm sàng năng, chăm sóc và điêu trị thường khó khăn, đòi hỏi tính chuyên khoa hoá cao. Nghiên cứu nhằm tổng kết và đánh giá thực trang về điêu trị và chăm sóc loại hình thương tổn phức tạp này. Phương pháp: Nghiên cứu mô tả cắt ngang; Kết

\footnotetext{
${ }^{1}$ Bệnh viện hữu nghị Việt Đức

Bênh viện đa khoa tỉnh Thanh Hoá

Chịu trách nhiệm chính: Phạm Hữu Lư

Email: phamhuulu@hmu.edu.vn

Ngày nhân bài: 9.7.2021

Ngày phản biện khoa họ: 3.9.2021

Ngày duyệt bài: 10.9.2021
}

Phạm Hữu Lưr1, Dương Văn Minh², quả nghiên cứu ghi nhận ở các biến số: Tuổi, giới tính, lâm sàng, cận lầm sàng, thời gian nằm viện, kết quá điều trị... Số liệu được ghi nhận vào mấu bệnh án nghiên cứu cho từng bệnh nhân và xử lý bằng chương trình SPSS 20.0. Kết quả: Từ tháng 01/2018 đễn 12/2020 có 34 bênh nhân chấn thương ngực có dẫn lưu màng phổi đởn thuần kèm theo chấn thương sọ não được chẩn đoán và điều trị tại Trung tâm Tim mạch và Lồng ngực - Bệnh viện hữu nghị Việt Đức. Thời gian từ khi được dẫn lưu màng phổi đến khi rút dẫn lưu trung bình là 7.3 ngày. Thời gian nằm viện trung bình là 10 ngày. Kết quả tốt chiếm $70.6 \%$. Kết luận: Chẫn thương ngực kèm theo chấn thương sọ não có dẫn lưu màng phổi đơn thuần là mốt trong những là một bệnh cảnh lâm sàng nặng, chăm sóc và điều trị đòi hỏi tính chuyên khoa. Kết quả chăm sóc và điều trị nhóm bệnh nhân nghiên cứu phản ánh thực 
trạng loại hình thương tổn phối hợp này và cho kết quả khả quan.

\section{SUMMARY \\ RESULTS OF TREATMENT OF CHEST TRAUMA AND HEAD TRAUMA WITH ALONE CHEST TUBE AT VIET DUC UNIVERSITY HOSPITAL \\ Background: Chest trauma and head trauma with alone chest tuble is a serious clinical condition, care and treatment is often difficult, requiring high specialization. The study aims to summarize and evaluate the current status of treatment and care for this complex lesion. Methods: Descriptive study; The research results were recorded in the following variables: age, sex, clinical, paraclinical, length of hospital stay, treatment results... The data were recorded in the research medical record for each patient and processed by the SPSS 20.0 program. Results: From January 2018 to December 2020, 34 patients with chest trauma and head trauma with alone chest tube were examined and treated at Cardiovascular and Thoracic Center- Viet Duc University Hospital. The average time of chest tube 7.3 days. The average hospital stays 10 days. Good results account for $70.6 \%$. Conclusion: Chest trauma and head trauma with alone chest tube is one of the serious clinical conditions, care and treatment requires expertise. The results of care and treatment of the studied group of patients reflect the reality of this type of combined injury and give positive results.}

\section{I. ĐẶT VẤN ĐỀ}

Chấn thương ngực (CTN) là một cấp cứu ngoại khoa thường gặp ở các bệnh viện lớn của tỉnh và thành phố, chiếm khoảng $7-10 \%$ cấp cứu ngoại khoa ${ }^{1,2}$. Chấn thương ngực là thương tích phổ biến thứ ba ở bệnh nhân chấn thương, sau chấn thương đầu và tứ chi, tỷ lệ tử vong là $10,8 \%$. Các nguyên nhân gây CTN thường gặp là do tai nạn giao thông, tai nạn lao động và tai nạn sinh hoạt, đặc biệt nguyên nhân do tai nạn giao chiếm tỳ lệ $\mathrm{cao}^{3,4}$. Chính vì vậy, CTN thường nằm trong bệnh cảnh đa chấn thương với nhiều tổn thương phối hợp kèm theo như chấn thương chi, chấn thương sọ não, chấn thương bụng kín ${ }^{5-7}$... Đặc biệt bệnh nhân chấn thương ngực có kèm theo chấn thương sọ não (CTSN) là một bệnh cảnh nặng nề, tiên lượng khó khăn trong việc điều trị và chăm sóc, có thể ảnh hưởng trực tiểp đến tính mạng bệnh nhân.

Để tìm hiểu thực trạng về vấn đề này chúng tôi thực hiện nghiên cứu đánh giá kết quả điều trị CTN có dẫn lưu khoang màng phổi (DLMP) có kèm theo CTSN nhằm làm rõ vấn đề nêu trên để góp phần nâng cao chất lượng điều trị tại các cơ sở ngoại khoa.

\section{II. ĐỐI TƯỢNG VÀ PHƯƠNG PHÁP NGHIÊN CỨU \\ Phương pháp nghiên cứu: Nghiên cứu mô}

tả cắt ngang, hồi cứu và tiến cứu

Đối tượng nghiên cứu: Tiêu chuẩn lựa chọn: Tất cả các bệnh nhân được chẩn đoán là CTN được dẫn lưu khoang màng phổi đơn thuần kèm theo CTSN được theo dôi và điều trị tại Trung tâm Tim mạch và Lồng ngực - Bệnh viện Hữu nghị Việt Đức, không phân biệt tuổi, giới tính, có đầy đủ trên hồ sơ bệnh án được lưu trũ theo quy định. Tiêu chuẩn loại trừ: Bệnh nhân CTN không được dẫn lưu khoang màng phổi; Bênh nhân CTSN nặng glasgow dưới 8 điểm; Bệnh nhân CTSN đã được phẫu thuật, bệnh nhân đã tử vong ngoại viện hoặc tử vong ngay trong giờ đầu vào viện; Bệnh nhân không đồng ý tham gia nghiên cứu; Bệnh nhân không có đủ hồ sơ bệnh án theo quy định

Các biến số dự kiến: Kết quả nghiên cứu ghi nhận ở các biến số: Tuổi, giới, lâm sàng, cận lâm sàng, tỷ lệ gây dính màng phổi; thời gian nằm viên...

Xử lý số liệu: Số liệu được ghi nhận vào mẫu bệnh án nghiên cứu cho từng bệnh nhân và xử lý bằng chương trình SPSS 20.0; Sử dụng phép kiểm định $\mathrm{T}$ - student để so sánh hai tỳ lệ giữa lô nghiên cứu và các tác giả khác

\section{KẾT QUẢ NGHIÊN CứU}

Từ tháng $01 / 2018$ đến $12 / 2020$, có 34 bênh nhân được chẩn đoán chấn thương ngực có kèm theo chẩn thương sọ não được dẫn lưu màng phổi với tỷ lệ là nam chiếm $79 \%$ và $21 \%$ là nữ. Tuổi thấp nhất là 16; cao nhất là 86 tuổi. Trung bình $49,5 \pm 18,8$ tuổi.

Bảng 1. Phân bố theo nguyên nhân tai
nạn
\begin{tabular}{|c|c|c|c|c|c|}
\hline Nguyên nhân & $\mathbf{n}$ & $\%$ & Tống & $\%$ \\
\hline $\begin{array}{c}\text { Tai } \\
\text { nạn } \\
\text { giao } \\
\text { thông }\end{array} \begin{array}{c}\text { Tự ngã } \\
\text { xe máy }\end{array}$ & 8 & 23.5 & & \\
\cline { 2 - 5 } & $\begin{array}{c}\text { Va chạm } \\
\text { với } \\
\text { khác }\end{array}$ & 16 & 47.1 & 24 & 70.6 \\
\hline Tai nạn lao động & 2 & 5.9 & 2 & 5.9 \\
\hline Tai nạn sinh hoạt & 8 & 23.5 & 8 & 23.5 \\
\hline Tống & $\mathbf{3 4}$ & $\mathbf{1 0 0}$ & $\mathbf{3 4}$ & $\mathbf{1 0 0}$ \\
\hline
\end{tabular}

Nhận xét: Tai nạn giao thông chiếm đa số trong các nguyên nhân tai nạn, chiếm $70.6 \%$, trong đó chủ yếu là va chạm với các phương tiện giao thông khác, chiếm $47.1 \%$. Tiếp đến là tai nạn sinh hoạt chiếm $23.5 \%$, chủ yếu nhất là ngã cao.

Về lâm sàng, các bệnh nhân bị cả CTN và CTSN nên triệu chứng cơ năng chính khi thăm khám là đau ngực $(94,1 \%)$ và đau đầu $(97.1 \%)$. Ho ra máu $(8.8 \%)$ xuất hiện ở các bệnh nhân có tổn thương đụng dập phổi. 
Trong nhóm bệnh nhân của chúng tôi: Tri giác khi vào viện với thang điểm Glasgow 14-15 điểm chiếm tỉ lệ chủ yếu $67.6 \%$. Có $32.4 \%$ bệnh nhân vào viện trong tình trạng lơ mơ, tiếp xúc chậm Glasgow 11-13 điểm.

Bảng 2. Phân bố dâu hiệu tại lồng ngực $(n=34)$

\begin{tabular}{|c|c|c|}
\hline Triệu chứng thực thể & $\mathbf{n}$ & $\mathbf{\%}$ \\
\hline Bầm tím, tụ máu, xây xát thành ngực & 24 & 70.6 \\
\hline Điểm đau chói khi nắn thành ngực & 33 & 97.1 \\
\hline Mảng sườn di động & 2 & 5.9 \\
\hline Tràn khí dưới da & 7 & 20.6 \\
\hline Rì rào phế nang giảm hoặc mất & 30 & 88.2 \\
\hline
\end{tabular}

Nhận xét: Triệu chứng đau nhói khi nắn thành ngực gặp ở đa số các bệnh nhân với tỉ lệ $97.1 \%$, rì rào phế nang giảm, mất cũng chiếm tỉ lệ cao với $88.2 \%$.

Bảng 3. Đặc điểm chung của gãy xương sườn ( $n=34)$

\begin{tabular}{|c|c|c|c|}
\hline \multicolumn{2}{|c|}{ Gãy xương sườn } & $\mathbf{N}$ & $\mathbf{\%}$ \\
\hline \multirow{2}{*}{$\begin{array}{c}\text { Vị trí ngực bị } \\
\text { tổn thương }\end{array}$} & Bên phải & 21 & 61.8 \\
\cline { 2 - 4 } & Bên trái & 10 & 29.4 \\
\cline { 2 - 4 } & Hai bên & 3 & 8.8 \\
\hline \multirow{2}{*}{$\begin{array}{c}\text { Số ố gãy trên } 1 \\
\text { xương }\end{array}$} & 1 & 30 & 88.2 \\
\hline \multirow{3}{*}{ Vị trí ổ gãy } & 2 & 4 & 11.8 \\
\cline { 2 - 4 } & Cung sau & 12 & 35.3 \\
\cline { 2 - 4 } & Cung bên & 29 & 85.3 \\
\cline { 2 - 4 } & Cung trước & 2 & 5.9 \\
\hline
\end{tabular}

Nhận xét: Ngực tốn thương gặp chủ yếu bên ngực phải với $61.8 \%$, có $8.8 \%$ trường hợp tổn thương cả 2 ngực. Số ổ gãy trên 1 xương chủ yếu là 1 ổ gãy chiếm $88.2 \%$. Vị trí gãy xương hay gặp nhất là gãy cung bên chiếm $85.3 \%$.

Bệnh nhân trong nghiên cứu đều được chụp phim cắt lớp sọ não để xác định tổn thương sọ não.

Bảng 4. Tổn thương sọ não trên phim cắt lớp $(n=34)$

\begin{tabular}{|c|c|c|}
\hline Tốn thương sọ não & $\mathbf{n}$ & $\mathbf{\%}$ \\
\hline Vỡ xương sọ & 13 & 38.2 \\
\hline Tụ máu ngoài màng cứng & 5 & 14.7 \\
\hline Tụ máu dưới màng cứng & 4 & 11.8 \\
\hline Tụ máu khoang dưới nhện & 15 & 44.1 \\
\hline Dập não & 13 & 38.2 \\
\hline Khí nội sọ & 4 & 11.8 \\
\hline
\end{tabular}

Nhận xét: Tổn thương hay gặp của chấn thương sọ não trong nhóm nghiên cứu là tụ máu khoang dưới nhện chiếm $44.1 \%$, tiếp đến là các tổn thương vỡ xương sọ và dập não chiếm $38.2 \%$. Bệnh nhân có thể bị hơn một thương tổn của sọ não. Bệnh nhân được thực hiện DLMP ở phòng mổ của phòng khám (phòng tiểu phẫu) chiếm 82.4\%. Có 6 trường hợp phải lên nhà mổ thực hiện dẫn lưu chiếm $17.6 \%$
Bảng 5. Thời gian từ khi vào viện đến khi DLMP

\begin{tabular}{|c|c|c|}
\hline Thời gian & $\mathbf{n}$ & $\mathbf{\%}$ \\
\hline$<6$ giờ & 13 & 38.2 \\
\hline $6-12$ giờ & 14 & 41.2 \\
\hline $12-24$ giờ & 3 & 8.8 \\
\hline$>24$ & 4 & 11.8 \\
\hline
\end{tabular}

Nhân xét: Đa số bênh nhân vào viện được dẫn lưu trong $12 \mathrm{~h}$ đầu chiếm tỉ lệ $79.2 \%$

- Lý liệu pháp hô hấp được thực hiện ngay sau khi bệnh nhân về bệnh phòng bao gồm vố rung $100 \%$, tập ho, khạc, thay đổi tư thế $100 \%$, thổi bóng được áp dụng cho 76.4\%. Biến chứng tại lồng ngực như xẹp phổi, máu đông màng phổi chiếm $14.6 \%$. Trong đó số bệnh nhân có máu đông màng phổi chiếm $11.8 \%$.

Bảng 6. Xử trí biến chứng tại lồng ngức sau dấn lưu màng phổi

\begin{tabular}{|c|c|c|}
\hline Biện pháp xứ trí & $\mathbf{n}$ & $\mathbf{\%}$ \\
\hline Xoay hút dần lưu & 5 & 14.7 \\
\hline Đặt thêm dấn lưu & 1 & 2.9 \\
\hline Lý liệu pháp tích cực & 5 & 14.7 \\
\hline Nội soi phế quạn & 2 & 5.9 \\
\hline $\begin{array}{c}\text { Mố nội soi ngực xử lý máu } \\
\text { đông màng phổ }\end{array}$ & 4 & 11.8 \\
\hline
\end{tabular}

Nhận xét. Các bệnh nhân có biến chứng sẽ được thực hiện lý liệu pháp tích cực và xoay hút dẫn lưu đều chiếm $14.7 \%$. Có 4 bệnh nhân chiếm $11.8 \%$ phải mổ nội soi xử lý biến chứng.

Bảng 7. Hình ảnh $x$ - quang ngực trước khi rút dẫn lưu.

\begin{tabular}{|c|c|c|}
\hline Kết quả X quang & $\mathbf{n}$ & $\%$ \\
\hline $\begin{array}{c}\text { Phối nở, hết khí hoặc } \\
\text { còn tù nhe góc sườn } \\
\text { hoành ở } 1 \text { hoăc } 2 \text { bên }\end{array}$ & 30 & 88.2 \\
\hline $\begin{array}{c}\text { Còn mờ rõ đáy phối ở 1 } \\
\text { hoặc 2 bên MP }\end{array}$ & 4 & 11.8 \\
\hline
\end{tabular}

Nhận xét: 4 BN còn mờ đáy phối rõ đều xảy ra ở các trường hợp có biến chứng. Măc dù đã cố gắng tập lý liệu pháp hô hấp + xoay DLMP nhưng $X$ quang ít cải thiện và dấn lưu không ra thêm dịch và khí, tình trạng lâm sàng ổn định, nên vẫn được quyết định rút dẫn lưu

- Thời gian từ khí dẫn lưu màng phổi đến khi rút dẫn lưu trung bình là $7.3 \pm 4.4$ ngày, trong đó ngắn nhất là 2 ngày và lâu nhất là 24 ngày.

- Thời gian nằm viện trung bình là $10 \pm 4.6$ ngày. Thời gian nằm viện ngắn nhất là 5 ngày, dài nhất là 26 ngày.

- Kết quả chung tốt chiếm $70.6 \%$, có 4 bệnh nhân (chiếm $11.8 \%$ ) có biến chứng ổ cặn phải mổ nội soi xử lý ổ cặn.

\section{BÀN LUÂ̂N}

Chấn thương ngực kèm theo chấn thương sọ 
não được dẫn lưu màng phổi là một bệnh cảnh phối hợp thường gặp trên lâm sàng, việc chăm sóc và điều trị gặp nhiều khó khăn, đặc biệt việc phối hợp thực hiện lý liệu pháp hô hấp trển các bệnh nhân này chưa tốt nên tî lệ biến chứng tại lồng ngực cao hơn so với các bệnh nhân chấn thương ngực đơn thuần khác. Qua nghiên cứu chúng tôi ghi nhận một số bàn luận như sau:

Đặc điểm chung: Giới tính: Tương tự như các nghiên cứu về CTN chung, nam giới luôn chiếm tỷ lệ cao hơn nhiều so với nữ giới. Tỷ lệ Nam / Nữ trong nghiên cứu này xấp xỉ $4 / 1$, còn theo Đặng Ngọc Hùng ${ }^{8}$ tỷ lệ nam/nữ là $7,2 / 1$ và Nguyễn Hữu Ước ${ }^{1}$ là $6.4 / 1$. Theo các tác giả, yếu tố chính gây sự chênh lệch giới tính này là nguyên nhân gây tai nạn - chủ yếu là tai nạn giao thông, với tỷ lệ nam giới lớn hơn so với nữ giới. Tuổi: Kết quả nghiên cứu cho thấy CTN kèm theo CTSN có thể gặp ở mọi lứa tuổi $(16-86)$, trong đó tỷ lệ gặp ở nhóm tuổi từ $20-60$ tuổi cao (58.8\%), với độ tuổi trung bình là 49.5 tuổi, kết quả này tương đương với nghiên cứu của YiPin Chou và Tzu-Chin Wu ${ }^{2}$, nghiên cứu về 61 bệnh nhân có đồng thời CTN và CTSN tại miền Nam Đài Loan. Nguyên nhân: Theo nghiên cứu của chúng tôi, nguyên nhân chấn thương do tai nạn giao thông chiếm $70.6 \%$. Theo Đặng Ngọc Hùng ${ }^{8}$ thì chấn thương ngực kín do tai nạn giao thông là 64.7\%; J Hugh Devitt ${ }^{9}$ trong một nghiên cứu ở Canada thấy tỷ lệ tai nạn giao thông là $70 \%$. Như vậy, tai nạn giao thông vẫn là yếu tố chính gây nên CTN nói chung cũng như CTN kèm các tốn thương khác nói riêng. Tuy nhiên, tỷ lệ nguyên nhân do tai nạn sinh hoạt cũng chiếm tới $23.5 \%$ trong nghiên cứu này, với các tai nạn như ngã cao (từ nhà cao tầng, cầu thang, cây cao), hoặc vật nặng đổ vào người. Kết quả này cũng phù hợp với tốc độ phát triển đô thị hóa trong giai đoạn hiện nay.

Lâm sàng và cận lâm sàng: Lâm sàng: Các bệnh nhân bị cả CTTN và CTSN nên triệu chứng cơ năng chính khi thăm khám là đau ngực $(94,1 \%)$ và đau đầu $(97,1 \%)$, đây là những triệu chứng dễ phát hiện, dấu hiệu chỉ điểm đầu tiền từ khi mới tiếp xúc với bệnh nhân, định hướng cho người thầy thuốc nghĩ đến các tổn thương ở lồng ngực và sọ não. Ho ra máu $(8,8 \%)$ xuất hiện ở các bệnh nhân có tổn thương đụng dập phổi. Các bệnh nhân trong nhóm nghiên cứu có tổn thương sọ não nhưng không quá nặng và không phải can thiệp ngoại khoa nên tri giác bệnh nhân lúc vào viện Ġlasgow 14-15 điểm chiếm tỉ lệ chủ yếu $67.6 \%$. Có $32.4 \%$ bệnh nhân vào viện trong tình trạng lơ mơ, tiếp xúc chậm
Glasgow 11-13 điểm. Tương tự như nghiên cứu của Yi-Pin Chou và Tzu-Chin Wư ${ }^{2}$, với thang điểm Glasgow trung bình là $11.74 \pm 3.26$; Khám lâm sàng tại lồng ngực: triệu chứng đau nhói khi nắn thành ngực gặp ở đa số các bệnh nhân với tỉ lệ $97.1 \%$, rì rào phế nang giảm, mất cũng chiếm tỉ lệ cao với $88.2 \%$. Có $20.6 \%$ bệnh nhân có tràn khí dưới da. Mảng sườn di động khám được ở 2 bệnh nhân chiếm $5.9 \%$, Theo Nguyễn Hữu Ước ${ }^{1}$ rì rào phế nang giảm hoặc mất là $97.4 \%$ và mảng sườn di động là $4.6 \%$. Các triệu chứng khi khám tại lồng ngực không có nhiều khác biệt so với các chấn thương ngực đơn thuần khác. Cận lâm sàng: Tất cả các bệnh nhân đều được chụp Xquang ngực để xác định các tổn thương tại lồng ngực: ngực tổn thương gặp chủ yếu bên ngực phải với $61.8 \%$, có $8.8 \%$ trường hợp tổn thương cả 2 ngực. Số ố gãy trên 1 xương chủ yếu là 1 ổ gãy chiểm $88.2 \%$. Vị trí gãy xương hay gặp nhất là gãy cung bên chiếm $85.3 \%$. Các tổn thương sọ não được xác định trên phim chụp cắt lớp vi tính, trong đó tổn thương hay gặp là tụ máu khoang dưới nhện chiếm $44.1 \%$, tiếp đến là các tổn thương vỡ xương sọ và dập não chiếm $38.2 \%$. Kết quả này cũng tương tự của Yi-Pin Chou và Tzu-Chin $\mathrm{Wu}^{2}$, với phần lớn tổn thương não của nhóm bệnh nhân này là tụ máu khoang dưới nhện.

Kết quả điêu trị: Dẫn lưu màng phổi: Đa số bệnh nhân được dẫn lưu trong $12 \mathrm{~h}$ đâu tính tữ lúc vào viện chiếm tỉ lệ $79.2 \%$, có $11.8 \%$ bệnh nhân được dẫn lưu trên 24h, sau một thời gian theo dõi tại khoa phòng. Thời gian từ khi dẫn lưu màng phổi đến khi rút dẫn lưu trung bình là $7.3 \pm 4.4$ ngày, trong đó ngắn nhất là 2 ngày và lâu nhất là 24 ngày. Kết quả này tương đương với tác giả Konstantina Chrysou ${ }^{6}$ nghiên cứu ảnh hưởng của chấn thương ngực trên các bệnh nhân đa chấn thương, thời gian đặt dẫn lưu màng phổi trung bình là 7.5 ngày. Biến chứng và xử trí: Có $14.6 \%$ số bệnh nhân trong nghiên cứu có các biến chứng tại lồng ngực. Mặc dù các bệnh nhân được chẩn đoán, dẩn lưu màng phổi sớm, được thực hiện lý liệu pháp hô hấp ngay sau khi về bệnh phòng nhưng do có CTSN kèm theo nên vấn đề phối hợp tập luyện, tập thở, thay đổi tư thế của các bệnh nhân là kém hơn so với nhóm nghiên cứu khác. Có 4 bệnh nhân có biến chứng máu đông màng phổi đã được phát hiện và phẫu thuật nội soi xử lý sớm, bệnh nhân khi ra viện vẫn đạt kết quả tốt, điêuu này tương ứng với các nghiên cứu của Yi-Pin Chou và TzuChin $\mathrm{Wu}^{2}{ }^{2}$ Ziapour ${ }^{10}$, thời gian phẫu thuật máu đông màng phổi sau chấn thương càng sớm kết 
quả càng tốt . Kết quả: Thời gian nằm viện trung bình là $10 \pm 4.6$ ngày. Thời gian nằm viện ngắn nhất là 5 ngày, dài nhất là 26 ngày. Kết quả chung tốt chiếm $70.6 \%$, có 4 bệnh nhân chiếm $11.8 \%$ có biến chứng máu đông màng phổi phải mổ nội soi xử lý ổ cặn. Theo kết quả của Nguyễn Hữu Ước ${ }^{1}$ và cộng sự thì thời gian nằm viện trung bình với nhóm bệnh nhân chấn thương ngực đơn thuần là $5,3 \pm 4,9$ ngày, tỷ lệ tốt là $89.9 \%$, không tốt là $5.7 \%$, còn theo Chrysou Konstantina ${ }^{6}$ và cộng sự với nhóm chấn thương ngực trên các bệnh nhân đa chấn thương thời gian nằm viện trung bình là 11 ngày, tương đương với kết quả nghiên cứu của chúng tôi.

\section{KẾT LUÂ̂N}

Chấn thương ngực kèm theo chấn thương so não có dẫn lưu màng phổi đơn thuần là một trong những là một bệnh cảnh lâm sàng nặng, chăm sóc và điều trị đòi hỏi tính chuyên khoa. Kết quả chăm sóc và điều trị nhóm bệnh nhân nghiên cứu phản ánh thực trạng loại hình thương tổn phối hợp này và cho kết quả khả quan.

\section{TÀl LIÊU THAM KHẢO}

1. Nguyễn Hữu Ước và công sự. Đánh giá tình hinh cấp cứu chấn thương lî̀ng ngực tại bệnh viện Việt Đức từ 2004 - 2006. Tạp chí Ý học Việt Nam. 2007;328:402-413.
2. Huang F-D, Yeh W-B, Chen S-S, et al. Early Management of Retained Hemothorax in Blunt Head and Chest Trauma. World J Surg. 2018;42(7):2061-2066.

3. Nguyễn Thế Hiệp, Lê Nữ Hòa Hiêp, Nguyễn Hoài Nam và cộng sự. Kết quả điểu trị chấn thương và vết thương ngực tại bệnh viện nhân dân Gia Định - TP.HCM. Tạp chí y học Việt Nam. 2008;352:483-490.

4. Zargar M, Khaji A, Karbakhsh Davari M Thoracic injury: a review of 276 cases. Chin J Traumatol. 2007;10(5):259-262.

5. Nguyê̂̉n Trường Giang, Nghiêm Đình Phấn, Nguyển Văn Sơn, Đăng Ngoc Hùng. Đăc điểm tôn thương và chiến thuật xự trí chấn thương ngực trong đa chấn thương. Tổng hội $Y$ Dược học. 2006; Ngoai khoa(6):12-17.

6. Chrysou K, Halat G, Hoksch B, Schmid RA, Kocher GJ. Lessons from a large trauma center: impact of blunt chest trauma in polytrauma patients-still a relevant problem? Scand J Trauma Resusc Emerg Med. 2017;25(1):42.

7. Hildebrand F, Giannoudis PV, Griensven M van, et al. Management of polytraumatized patients with associated blunt chest trauma: a comparison of two European countries. Injury. 2005;36(2):293-302.

8. Đặng Ngọc Hùng và cộng sự. Một số nhận xét về đắc điểm triêuu chứng, sơ cứu và cấp cứu chấn thương ngực kín qua 139 trường hợp tại bệnh viện 103. Tap chí ngoại khoa. 2006;56(6):2-11.

9. J. Hugh Devitt. Blunt Chest Trauma: Anaesthesia, assessment and management. In: Can J Anaesth. 40th ed.; 1993:29-39.

\section{VAI TRÒ CỦA CEA TRONG ĐÁNH GIÁ ĐÁP ỨNG HÓA TRI UNG THƯ ĐẠI TRỰC TRÀNG GIAI ĐOẠN TÁI PHÁT, DI CĂN}

\section{TÓM TẮT}

Mục tiêu nghiên cứu: Đánh giá vai trò của carcinoembryonic antigen (CEA) trong việc theo dõi đáp ứng khối u với hóa trị trong điêu trị ung thư đại trực tràng (UTĐTT) giai đoạn tái phát, di cắn không mổ được tại khoa Nội 4 Bệnh viện $K$ từ tháng 7/2017đến tháng 7/2021. Đối tượng và phương pháp nghiên cứu: Nghiên cứu mô tả hồi cứukết hợp với tiến cứu trên 81 bênh nhân UTĐTT giai đoạn tái phát, di căn không mổ được có tăng CEA >5ng/ml trước điều trị, sử dụng hóa chất phác đồ có Oxaliplatin hoặc Irinotecan làm nền, 6 chu kì hóa trị. Nông độ

${ }^{1}$ Trương Đại học Y Hà Nội

²Bênh viện $K$ Tân Triều, thành phố Hà Nội.

${ }^{3}$ Bệnh viện Ung Bướu Hà Nội, thành phố Hà Nội.

Chịu trách nhiệm chính: Phan Văn Quân

Email: Phanquanhmu@gmail.com

Ngày nhận bài: 9.7.2021

Ngày phản biên khoa họ: 3.9.2021

Ngày duyệt bài: 10.9.2021
Phan Văn Quân ${ }^{1}$, Trần Thắng², Bùi Vinh Quang ${ }^{3}$

CEA huyết tương và chụp cắt lớp vi tính (CLVT) được thực hiện trước điều trị và sau mỗi 03 chu kì hóa trị. Kết quả: Độ nhạy, độ đặc hiệu, giá trị dự đoán dương tính, âm tính, độ chính xác chẩn đoán của việc đánh giá đánh ứng bằng CEA đối với bênh đáp ứng hoàn toàn và một phân lần lượt là $82,0 \%, 63,1 \%$, $63,1 \%, 82,0 \%, 71,3 \%$, đối với bểnh tiến triên lần lướt là $61,1 \%, 80,4 \%, 36,7 \%, 91,8 \%$. Kết luận: Nồng độ CEA huyết thanh có thể cung cấp thông tin hữu ích trong đáp giá bệnh đáp ứng và tiến triển ở bệnh nhân UTĐTT giai đoạn tái phát, di căn không mổ được có tăng CEA trước điều trị.

Tư khóa: ung thư đại tràng, trực tràng, giai đoạn tái phát, di căn, CEA.

\section{SUMMARY \\ THE ROLE OF CARCINOEMBRYONIC ANTIGEN FOR MONITORING TUMOUR RESPONSE DURING CHEMOTHERAPY IN RECURRENT, METASTATIC COLORECTAL CANCER \\ Aims: To evaluate the efficacy of carcinoembryonic antigen (CEA) for monitoring tumour}

